\title{
Personal Leadership Resources as Mediator of Context and Leadership Practice: A Review and Conceptual Analysis
}

\author{
T. J. Hoogsteen \\ T.J. Hoogsteen, Box 25, Cut Knife, SK, S0M 0N0.
}

\begin{abstract}
Hallinger (2018) contends that context has been treated as a 'given' in reviews of research and remains in the shadows of leadership. At the same time, Lee and Hallinger (2012) have described an emerging area of study focusing on the impact of organizational contexts. Several scholars in the field of educational leadership have gone as far as to say that context is causal. However, a recent review of empirical research by Leithwood, Harris, and Hopkins (2019) claimed that the ways in which leaders apply basic leadership practices demonstrate a responsiveness to, rather than dictation by, context. Furthermore, they note that a well-defined set of 'personal leadership resources' show promise of explaining a high proportion of variation of school leaders' practice. These two claims, while not diminishing the significance of context, demonstrate the importance of a leader's characteristics and leadership practice to leaders that are successful. To consider this latter point further, a review of literature is conducted to synthesize three areas in the field of educational leadership which, at least implicitly, are considered competing; context, leadership practice, and personal leadership resources. The review results in an adaptation of previous models from Bossert et al. (1982) and Hallinger (2018) that illustrates the convergence of the three leadership variables.
\end{abstract}

Key Words: Context, Leadership, Personal Leadership Resources

\section{INTRODUCTION}

Hallinger (2018) recounts a story of a lecture on effective school leadership where an attendee posed the basic question, and one many practicing leaders and educators want answered, "How do I apply these findings in my context"? The premise of this question, can be paraphrased as principals' leadership activities and success of those activities are largely dependent on the context in which they work. Answering that question has been at the heart of research on educational leadership for many years, yet a definitive conclusion has been elusive. This paper is written with the purpose of helping scholars and practitioners craft explanations to this leadership problem that address the multi-faceted nature of the issue.

Leithwood, Harris, and Hopkins (2008) acknowledge that most successful school leaders employ the same basic practices, but they further this claim by noting that how the practices are applied demonstrates responsiveness, rather than dictation, to the contexts in which they work. They go on to allude to the body of work related to the importance of sensitivity to context for school leaders 
and how some would argue that 'context is everything'. Eacott (2019) argues that although claims regarding context are often unclear, they remain undeniable, and he goes as far to say that context is 'causal'. In the recent revisiting of their classic 2008 article, Leithwood, Harris, and Hopkins (2019) update many of the original claims, but, the aforementioned claim remained in its original form.

Despite the above recognition of the importance of context, Hallinger (2018) asserts that context has been treated as a 'given' in reviews of research and remains in the shadows of leadership. On this point, Harris and Jones (2017) concur, and state that contextual and cultural influences are, for the most part, missing in the debate about educational change and reform (p. 635). Eacott (2019) furthers this argument by declaring that it is common that educational administration and leadership is centered on the ability of leaders to overcome context, whereas the less common view is that there are significant limitations on what can be accomplished and the value attributed to leadership is negligible in comparison to external social structures.

However, the views espoused in Eacott (2019), Hallinger (2018), and Harris and Jones (2017) are not new, and similar remarks have been made for nearly the last 50 years. For example, Bridges (1970) and Hallinger, Bickman, and Davis (1996) drew comparable conclusions. While maintaining the view that macrolevel contexts continue to be a blind spot, Lee and Hallinger (2012) outlines a burgeoning effort to explain the impact of organizational contexts on school leadership (p. 462). Even though context may be considered as assumed in much of the literature related to educational leadership and management, as Clarke and O'Donoghue (2017) point out, context has long been an emphasis in the field of comparative education. Regardless, in response to this perceived gap, Hallinger (2018) adapted the Far West Lab instructional model (see Figure 1) originally put forth by Bossert et al. (1982).

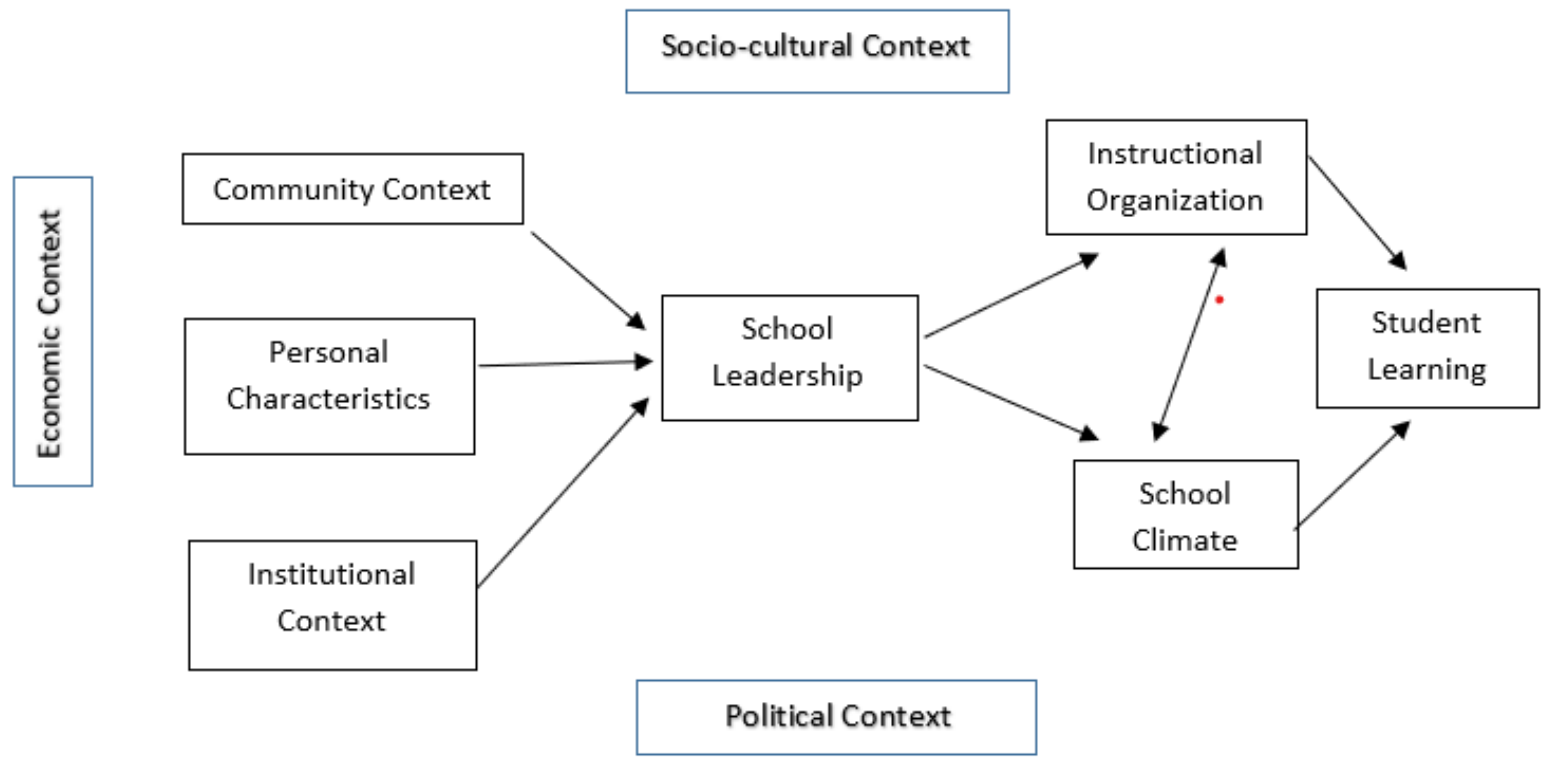

Figure 1. Adaptation of the Far West Lab instructional management model (Hallinger, 2018, p. 17). 
Hoogsteen, T. J. (2020). Personal Leadership Resources as Mediator of Context and Leadership Practice: A Review and Conceptual Analysis. Advances in Social Sciences Research Journal, 7(4) 24-34.

Framed as a research-informed conceptual analysis, the purpose of Hallinger (2018) was to examine school contexts' influence on leadership and how leaders adapt their practice to varying contexts. The aforementioned analysis addressed one gap in the leadership literature and brought context to the forefront. However, it left another, which this paper, a research-informed conceptual analysis as well, will attempt to bridge through an overview of relevant research, discussion contributing to and extending understanding of influences on leadership practice and supporting the forthcoming argument, and a revisiting of the previous reconsidered model presented in Hallinger (2018). In doing so, the aim is to reconcile three areas of research in educational leadership and administration that are often seen, at least implicitly, as competing.

In their review of empirical research related to context, Clarke and O'Donaghue admit that they do not explicitly refer to leaders' personal traits being pertinent to the ways in which leadership practice is enacted within a given setting. The same can be said about the way personal characteristics are dealt with in Hallinger (2018). Defined as knowledge, skills, and experience leaders bring to the job, personal characteristics and resources act as a prism through which information and problems are interpreted (Hallinger, 2018, p. 7). Although included in the mentioned model, personal characteristics are depicted a person-specific context rather than a variable affected by context which in turn influence or determine leadership practice. However, analysis reveals personal characteristics seem to be separate from context. For example, Kutz (2008), who coined the term contextual intelligence, notes that diagnosing contexts is an individual's skill and is not directly an organizational phenomenon. Even though not all contexts are organization related, the idea that ability to diagnose and work within given contexts depends on the individual's skill is important and provides distinction between context and an individual's characteristics.

The absence of expressly including leaders' characteristics, combined with claims set out in Leithwood et al. (2019) inspired this new analysis. First, referring back to the claim mentioned in the opening paragraph that most successful school leaders employ the same basic practices, but ways in which the practices are applied demonstrates responsiveness, rather than dictation (italics used for emphasis), to the contexts in which they work. This claim, fused with their final claim that a well-defined set of 'personal leadership resources' show promise of explaining a high proportion of variation of school leaders' practice, provide the grounding for the argument that personal characteristics, or personal leadership resources, while not diminishing the importance or effects of context, act as a mediator of context and leadership practice.

\section{OVERVIEW}

The section that follows provides a brief overview, not an exhaustive literature review, of pertinent research regarding the three areas to be highlighted in the revisited model depicting influences on leadership practice to be presented at the end. The topics to be discussed, and those areas often thought of to be at odds, are personal leadership resources, context, and leadership practices.

\section{Personal Leadership Resources}

Interest in leadership traits or characteristics has a long history in leadership literature and was one of the first systematic attempts to study leadership (Northouse, 2016). The $20^{\text {th }}$ century saw periods of interest and disinterest in trait theory. Apathy toward trait theory stems from several criticisms including a failure to adequately include context and create a comprehensive and valid 
trait framework (Judge, Piccolo, \& Kosalka, 2009). Popular works such as Brown (2018) place the focus on one characteristic such as vulnerability but still fail to provide an all-inclusive model of essential leadership traits. On the other hand, Judge et al. (2009), based on the work of Zaccaro, Kemp, and Bader (2004), discusses ten traits. These traits are conscientiousness, extraversion, agreeableness, emotional stability, openness to experience, core self-evaluations, intelligence, charisma, narcissism, hubris, social dominance, and Machiavellianism.

The first six traits on the list are considered bright traits while the latter four are termed dark traits. Later work by Colbert, Judge, Choi, and Wang (2012), narrows and tests five of these traits, neuroticism, extraversion, openness to experience, conscientiousness, and agreeableness. In their study four out of the five traits were positively linked to leadership emergence and effectiveness with only neuroticism failing to have a positive effect. Leithwood et al. (2019) notes that these findings have been reported consistently. Notwithstanding positive results, the approach is not without criticism and limitations. Specifically speaking, Colbert et al. (2012) used observer ratings from people well-known to participants and focused on a limited number of behaviours such as idea generation to measure leadership emergence. In addition, Judge et al. (2009) emphasizes the heritability of leadership traits.

Conversely, Goleman, Boyzatis, and McKee (2013) is founded on a leader's ability to develop traits to be successful and also provides a framework of emotional intelligence (EI) and consists of two domains, personal competence and social competence. These are supplemented by two competencies in each domain referred to as self-awareness and self-management, and social awareness and relationship management respectively. EI theory integrates trait theory and a skills approach developed by Zaccaro, Mumford, Connelly, Marks, and Gilbert (2000). This approach included three competencies called problem-solving skills, social judgement skills, and knowledge. While Emotional intelligence theory integrates both a trait and skills approach to leadership, it also bares resemblance to an emerging area of interest in personal qualities of leaders' that are nonbehaviour and non-practice related known as personal leadership resources (see Figure 2 for a comparison of the two theories). There are three main types of personal leadership resources which are cognitive resources, social resources, and psychological resources. Each type is further broken down. For example, cognitive resources include problem solving expertise and domainspecific knowledge while social resources contains perceiving emotions, managing emotions, and acting in emotionally appropriate ways. The final category, psychological resources, houses optimism, self-efficacy, resilience, and proactivity (Leithwood, 2017). For the purposes of this analysis, personal leadership resources will be used.

\section{Context}

To this section, two sources are particularly relevant as they examine and explain different types of contexts in which schools exist. The first study, by Braun, Ball, Maguire, and Hoskins (2011) centered on four dimensions of context:

1. Situated Contexts (such as locale, school histories, intakes and settings)

2. Professional Contexts (such as values, teacher commitments and experiences, and 'policy management' in schools).

3. Material Contexts (e.g. staffing, budget, buildings, technology, and infrastructure). 
Hoogsteen, T. J. (2020). Personal Leadership Resources as Mediator of Context and Leadership Practice: A Review and Conceptual Analysis. Advances in Social Sciences Research Journal, 7(4) 24-34.

4. External Contexts (e.g. degree and quality of local authority support, pressures and expectations from broader policy context, such as Ofsted ratings, league table positions, legal requirements and responsibilities) (p. 598).

While applicable, Braun et al. (2011) was mainly concerned with contexts affecting policy enactment. Hallinger (2018) however, named six different, albeit similar contexts, directly related to the provision of leadership in schools. The six contexts are:

1. Institutional (school district's aims. Structures, initiatives, size, norms and degree of centralization).

2. Community (socio-economic status, parental involvement, rural or urban, and conflict).

3. National Cultural (regional and international politics and economics, hierarchical arrangement).

4. Economic (facilities, technology, teacher quality),

5. Political (political aims of the society).

6. School Improvement (History of the school and the relative achievement and culture of the school over time).

As mentioned, even though the articles present two different sets of contexts and each had separate aims, Clarke and O'Donoghue (2017) recognized that educational leadership and context are inseparable while reviewing the contexts listed in Braun et al. (2011). While both arrangements of contexts would be suitable for use in this contextual analysis, considering their similarity and that the article proposes modification to the model used in Hallinger (2018), it is those contexts that will be adopted.

\section{Leadership Practices}

Returning to a main influence of this article, Leithwood et al. (2008) claim that most successful leaders enact the same basic leadership practices. While revisiting their original assertions, Leithwood et al. (2019) found that no revisions to the original claim were necessary. Four domains of practice, regardless of context, were found to be used by successful leaders. The domains include setting directions, building relationships and developing people, developing the organization to support desired practices, and improving the instructional program. What has changed though, is that the number of specific leadership practices within the domains have increased from 14 to 22 over the last decade. Table 1 has the complete list of leadership practices. 
Table 1. What successful leaders do (Leithwood et al., 2019, p. 4).

\begin{tabular}{ll}
\hline Domains of Practice & Specific Leadership Practices \\
\hline & \\
& Build a shared vision \\
Set Directions & Identify specific, share, short-term goals \\
& Create high-performance expectations \\
& Communicate the vision and goals
\end{tabular}

Build Relationships and Develop People

Develop the Organization to Support Desired Practices

Improve the Instructional Program
Stimulate growth in the professional capacities of staff

Provide support and demonstrate consideration for individual staff members

Model the school's values and practices

Build trusting relationships with and among staff, students and parents

Establish productive working relationships with teacher federation representatives

Build collaborative culture and distribute

leadership

Structure the organization to facilitate

collaboration

Build productive relationships with families and communities

Connect the school to its wider environment

Maintain a safe and healthy school environment

Allocate resources in support of the school's vision and goals

Staff the instructional program

Provide instructional support

Monitor student learning and school improvement progress

Buffer staff from distractions to their instructional work

Overall, the literature agrees on the effectiveness of leadership practice listed here. Although different authors will apply different names to the domains or practices, the similarities are glaring. For example, an original conception of instructional leadership practice by Hallinger (2005) listed seven categories of practice including creating a shared sense of purpose, fostering continuous improvement, coordinating curriculum, shaping the reward structure, developing a climate of high expectations, organizing and monitoring aimed at developing staff, and being a visible presence. Robinson (2011) synthesized a comparable list composed of five student-centered leadership dimensions. According to this work, the five dimensions are establishing goals and expectations, resourcing strategically, ensuring quality teaching, leading teacher learning and development, 
Hoogsteen, T. J. (2020). Personal Leadership Resources as Mediator of Context and Leadership Practice: A Review and Conceptual Analysis. Advances in Social Sciences Research Journal, 7(4) 24-34.

ensuring an orderly and safe environment. With the similarities in mind and for the sake of the current analysis, the domains and practices set out in Leithwood et al. (2019) will be employed.

\section{DISCUSSION}

It would be remiss to state that personal leadership resources and their contribution to leadership practices have not been considered. For example, Robinson (2011) sought to overlay three capabilities, to go with the five student-centered leadership dimensions. The capabilities were termed applying relevant knowledge, solving complex problems, and building relational trust. When described, these three capabilities resemble cognitive and social personal leadership resources. Similarly, Leithwood (2017) addressed leadership practices and personal leadership resources in relation to the Ontario Leadership Framework. In both works leadership practice and capabilities were brought together, but context was either assumed or scantly addressed. For example, Robinson (2011) contends that capabilities such as problem-solving skills are required in order to address issues in unique contexts (p.22), but other than that, context is mainly relegated to the background. Conversely, Clarke and O'Donaghue (2017) discuss context and leadership practice but admit that characteristics and the effects they have on leadership practice is not considered.

Through review, to the best of my knowledge no such work exists that endeavours and succeeds in creating a conceptual model which reconciles context, leadership practice, and personal leadership resources. The closest is an analysis conducted by Goldring, Huff, May, and Camburn (2007). The authors examined how the individual attributes of 46 principals related to leadership practice and context. The attributes measured were knowledge operationalized as perceived competence, background characteristics such as number of years of experience and gender, and a report of principals' assessment of the quality and impact of their professional development. The results were obtained from a daily, end-of-day log that was completed over a one-week period. A conclusion drawn from the study was that principal's attention to responsibilities varied depending on context but did not differ according to school leaders' attributes. A similar study placed leadership behavior in the context of the school organization and environment, however, the study was limited in terms of measures of personal characteristics. At the time, the researchers only considered principal gender and years of teaching experience as antecedent variables (Hallinger et al., 1996).

Despite their results, Goldring et al. (2007) noted that their work underscores the need for continued analysis of leaders' characteristics. Considering the attributes used in the aforementioned studies and current understanding of personal leadership resources further analysis is justified. The argument can be further supported when the statement from Goldring et al. (2007) is combined with claims from Leithwood et al. (2019) that successful leaders employ the same basic practices and that the application of practices indicate responsiveness, rather than dictation, to context, and that personal leadership resources have a potential to explain a large proportion of variation in practice. Examining the research behind context and leadership practice and personal characteristics and leadership practice can provide insight and support for the argument that personal leadership resources act as a mediator of context and leadership practice. 


\section{Context and Leadership Practice}

To help answer the question which was posed in the introduction, "How do I apply these findings in my context"? (Hallinger, 2018), the article now draws upon existing research in the field, much of which was mentioned earlier such as, but not limited to, Dwyer (1985), Hallinger et al. (1996), Lee and Hallinger (2012) and are based on very similar beliefs. Assuming the premise that leadership activities and their effectiveness are contingent on context is true, we also know that school leaders engage in common behaviours and that they vary their behaviours' form and function to suit their contexts and purposes (Dwyer, 1985; Leithwood et al., 2019). In proposing a theory of contextual leadership, Osborn, Hunt, and Jauch (2002) further note that leaders, individually and/or collectively shape an organization's focus via selection of processes and interpretation of what needs to be done, and that leaders have an important say in what types of outcomes should be pursued. Statements and finding such as these denote that leaders have at least some agency in how leadership is practiced, and thus the level of effectiveness of such actions. An appropriate answer to the question "How do I apply these findings in my context?" would then be that we know that leadership practices as set out in Leithwood et al. (2019) are effective regardless of the context, but it is up to school leadership to adapt those practices to suit the particular context.

\section{Leadership Practice and Personal Leadership Resources}

A follow-up question that could arise from the last statement might be "How do I know how to adapt the practices to suit my context"? Responding definitively based on available literature may prove difficult, however, some generalizations from related work may prove to be useful. In their work which highlights a cognitive perspective pertaining to policy implementation, Spillane, Reiser, and Reimer (2002), note that policy messages about changing behavior is not a given that resides in the policy signal as much as the agents must first notice, frame, interpret, and construct meaning for such messages. In this way, policy implementation is highly dependent on prior knowledge. In other words, this last statement can be generalized as leaders depend on personal leadership resources such as prior knowledge to make decisions about situations affecting their school. Louis and Robinson (2012), in their study relating to external mandates, implementation, and instructional leadership, made a finding to support the last statement as well. They noted that school leaders differed significantly in the educational and instructional knowledge that they brought to the enactment of the external agenda. Leaders who were proficient instructional leaders brought more knowledge to implementation than those with less instructional leadership capabilities and this difference resulted in a substantial variation in how they led the work (p. 657). Recent research by Leithwood (2013), points to two personal leadership resources in particular, proactivity, and systems thinking, both of which are heavily dependent on knowledge of leadership practice and knowledge of the various contexts in which the leader is situated. The report, aimed at leadership at the district level, further notes that evidence suggest that personal leadership resources are becoming increasingly important for leadership success because leadership and the contexts in which it is exercised is becoming more varied and complex. Although the report was commissioned for district leaders in Ontario, Canada, it can be reasonably applied to individual school contexts as well. A very general response to the opening question in this paragraph then would be "adapt the practice to suit your context by taking your knowledge about your context and your knowledge of what works in practice of leadership and apply it to your problem of practice". 


\section{CONCLUSION}

When referring back to the question in the opening paragraph, "How do I apply these findings in my context" the argument that personal leadership resources act as a mediator of context and leadership practice needs to acknowledged. Solving problems of practice related to leadership requires more complex answers than just context is causal or a listing of traits or effective leadership practice. Claims made in Leithwood et al. (2019) that there are effective leadership practices regardless of context, effective leaders are responsive to context, and that certain personal leadership resources explain a high proportion of variation in practice lend credence to the idea effective leadership resides at the intersection of context, personal leadership resources, and leadership practice. Figure 2 is a modification of Hallinger (2018) to illustrate this convergence. Future research should be directed at all three areas of practice and their interaction rather than treating each as separate. Attending to this perceived need will not only assist practicing leaders make informed decisions regarding their practice but also help in developing future leaders.

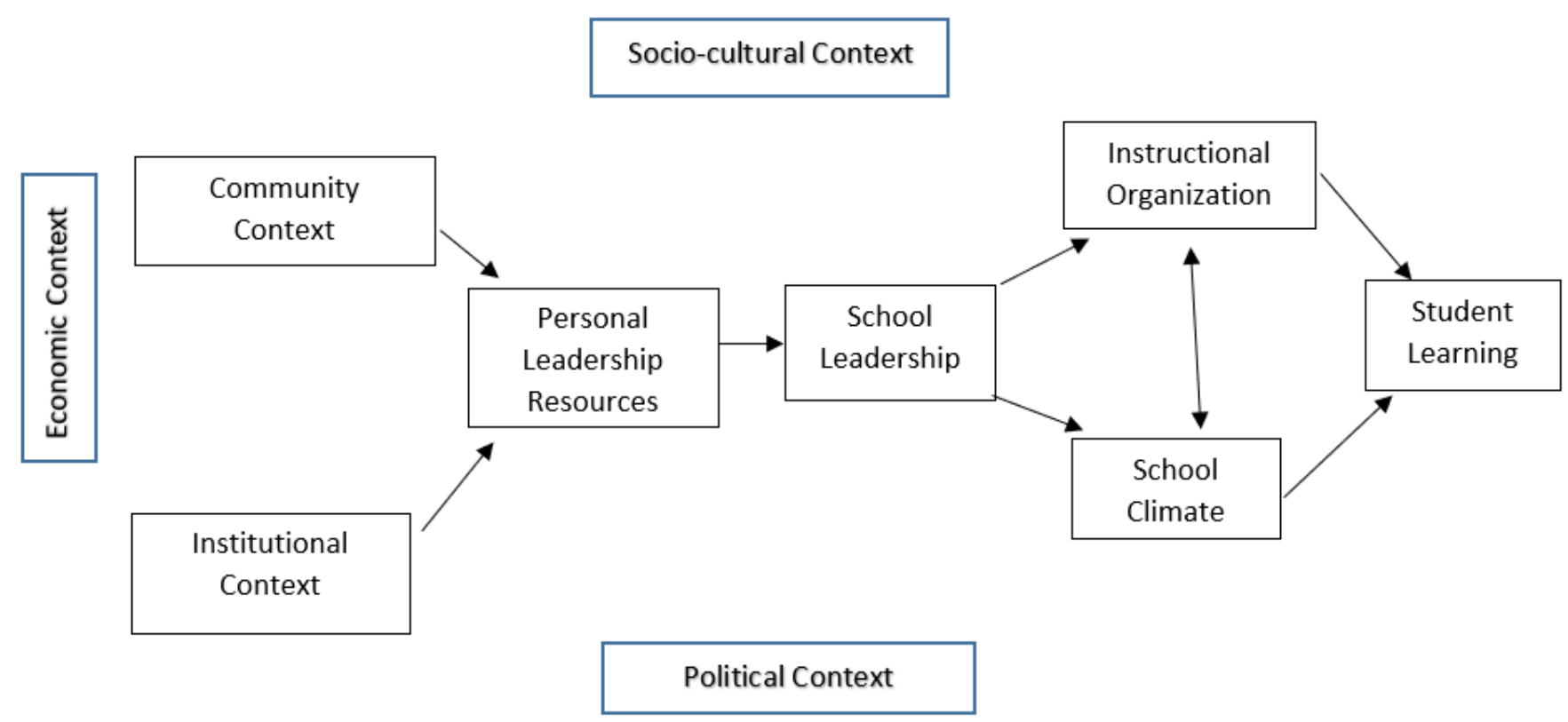

Figure 2. Adaptation of the Far West Lab instructional management model (Bossert et al., 1982) and Hallinger (2018) to illustrate the mediating role of personal leadership resources between context and school leadership practice. 


\section{References}

Bossert, S., Dwyer, D., Rowan, B., \& Lee, G. (1982). The instructional management role of the principal. Educational Administration Quarterly, 18(3), 34-64.

Braun, A., Ball, S., Maguire, M., \& Hoskins, K. (2011). Taking context seriously: Towards explaining policy enactments in the secondary school. Discourse: Studies in the Cultural Politics of Education, 32(4), 585-596.

Bridges, E. (1970). Administrative man: Origin or pawn in decision making? Educational Administration Quarterly, 6, 7-25.

Clarke, S., \& O’Donoghue, T. (2017). Educational leadership and context: A rendering of an inseparable relationship. British Journal of Educational Studies, 65(2), 167-182.

Colbert, A., Judge, T., Choi, D., \& Wang, G. (2012). Assessing the trait theory of leadership using self and observer ratings of personality: The mediating role of contributions to group success. The Leadership Quarterly, 23, 670-685.

Dwyer, D. (1985). Understanding the principal's contribution to instruction. Peabody Journal of Education, 63(1), 318.

Eacott, S. (2019). Starting points for a relational approach to organizational theory: An overview. Research in Educational Administration \& Leadership, 4(1), 16-45.

Goldring, E., Huff, J., May, H., \& Camburn, E. (2008). School context and individual characteristics: What influences principal practice? Journal of Educational Administration, 46(3), 332-352.

Goleman, D., Boyatzis, R., \& McKee, A. (2013). Primal leadership: Unleashing the power of emotional intelligence. Boston, MA: Harvard Business Review Press.

Hallinger, P. (2005). Instructional leadership and the school principal: A passing fancy that refuses to fade away. Leadership and Policy in Schools, 4, 221-239.

Hallinger, P. (2018). Bringing context out of the shadows of leadership. Educational Management \& Leadership, 46(1), $5-24$.

Hallinger, P., Bickman, L., \& Davis, K. (1996). School context, principal leadership, and student reading achievement. The Elementary School Journal, 96(5), 527-549.

Harris, A., \& Jones, M. (2017). Leading in context: Putting international comparisons into perspective. School Leadership and Management, 37(5), 431-433.

Judge, T., Piccolo, R., \& Kosalka, T. (2009). The bright and dark side of leader traits: A review and theoretical extension of the leader trait paradigm. The Leadership Quarterly, 20, 855-875.

Kutz, M. (2008). Toward a conceptual model of contextual intelligence: A transferable leadership construct. Leadership Review, 8, 18-31.

Lee, M., \& Hallinger, P. (2012). National contexts influencing principal's time use and allocation: economic development, societal culture, and educational system. School Effectiveness and School Improvement, 23(4), 461-482.

Leithwood, K. (2013). Strong districts and their leadership. The Institute for Education Leadership: Ontario.

Leithwood, K. (2017). The Ontario leadership framework: Successful school leadership practices and personal leadership resources. In Leithwood, K., Pollock, K., \& Sun, J. (Eds.), How school leaders contribute to student success: The four paths framework (31- 43). Cham, Switzerland: Springer.

Leithwood, K., Harris, A., \& Hopkins, D. (2008). Seven strong claims about successful school leadership. School Leadership and Management, 28(1), 27-42.

Leithwood, K., Harris, A., \& Hopkins, D. (2019). Seven strong claims about successful school leadership revisited. School Leadership and Management, 1-19.

Louis, K., \& Robinson, V. (2012). External mandates and instructional leadership: School leaders as mediating agents. Journal of Educational Administration, 50(5), 629-655.

Northouse, P. (2016). Leadership: Theory and practice (7th ed.). Thousand Oaks, CA: Sage Publications. 
Hoogsteen, T. J. (2020). Personal Leadership Resources as Mediator of Context and Leadership Practice: A Review and Conceptual Analysis. Advances in Social Sciences Research Journal, 7(4) 24-34.

Osborn, R., Hunt, J., \& Jauch, L. (2002). Toward a contextual theory of leadership. TheLeadership Quarterly, 13, 797837.

Robinson, V. (2011). Student-centered leadership. San Francisco, CA: Jossey-Bass.

Spillane, J., Reiser, B., \& Reimer, T. (2002). Policy implementation and cognition: Reframing and refocusing implementation research. Review of Educational Research, 72(3), 387- 431.

Zaccaro, S., Kemp, C., \& Bader, P. (2004). Leader traits and attributes. In Antonakis, J., Cianciolo, A., \& Sternberg, R. (Eds.), The nature of leadership (101-124). Thousand Oaks, CA: Sage.

Zaccaro, S., Mumford, M., Connelly, M., Marks, M., \& Gilbert, J. (2000). Assessment of leader problem-solving capabilities. Leadership Quarterly, 11(1), 37-64. 